Oxygen-Permeable Ceramic Membranes for Gas Separation*

$$
\text { ANLET/CP- } 95503
$$

U. Balachandran, B. Ma, P. S. Maiya, J. T. Dusek,

R. L. Mieville, and J. J. Picciolo

Energy Technology Division, Argonne National Laboratory

Argonne, Illinois 60439

February 1998
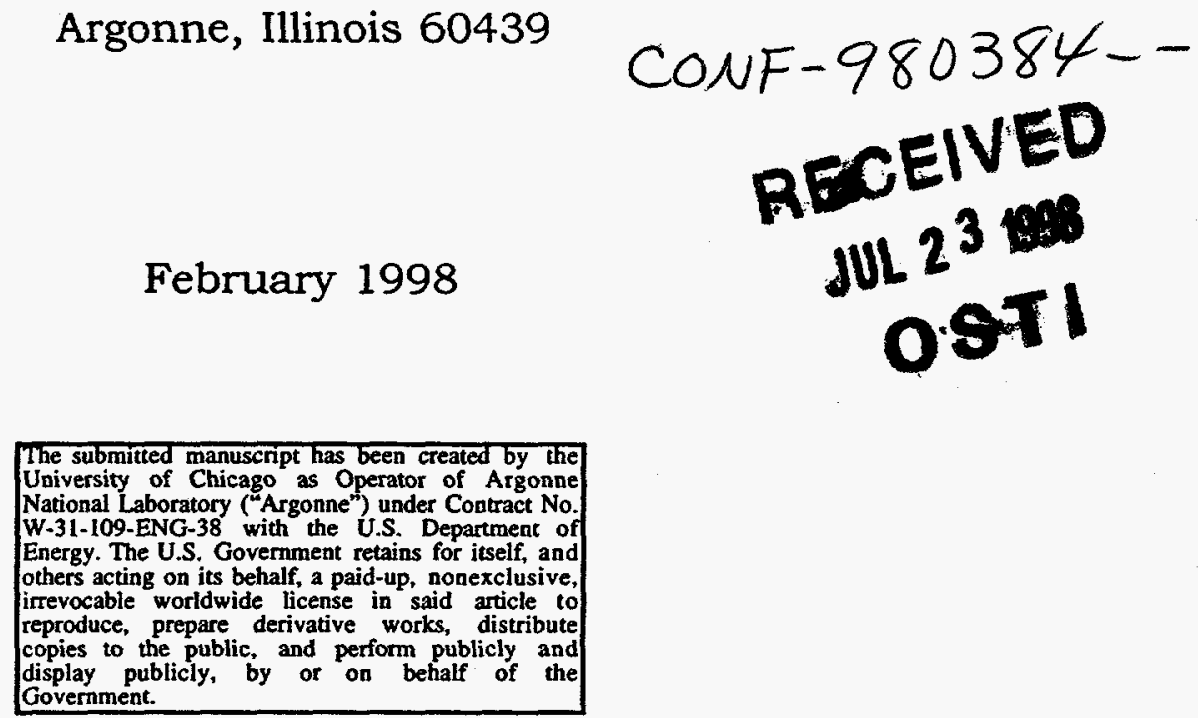

Paper for US-Japan Workshop on Electrically Active Ceramic Interfaces, Massachusetts Institute of Technology, Cambridge, MA, March 17-19, 1998.

*Work at Argonne National Laboratory is supported by U.S. Department of Energy, Federal Energy Technology Center, under Contract W-31-109-Eng-38. 


\section{DISCLAIMER}

Portions of this document may be illegible electronic image products. Images are produced from the best available original document. 


\title{
Oxygen-Permeable Ceramic Membranes for Gas Separation
}

\author{
U. Balachandran, B. Ma, P. S. Maiya, J. T. Dusek, R. L. Mieville, and J. J. Picciolo \\ Energy Technology Division, Argonne National Laboratory, Argonne, Illinois 60439, USA
}

\begin{abstract}
Mixed-conducting oxides have a wide range of applications, including fuel cells, gas separation systems, sensors, and electrocatalytic equipment. Dense ceramic membranes made of mixed-conducting oxides are particularly attractive for gas separation and methane conversion processes. Membranes made of $\mathrm{Sr}-\mathrm{Fe}-\mathrm{Co}$ oxide, which exhibits high combined electronic and oxygen ionic conductivities, can be used to selectively transport oxygen during the partial oxidation of methane to synthesis gas (syngas, i.e., $\mathrm{CO}+\mathrm{H}_{2}$ ). We have fabricated tubular $\mathrm{Sr}_{2} \mathrm{Fe}_{2} \mathrm{CoO}_{6+\delta}$ membranes and tested them (some for more than $1000 \mathrm{~h}$ ) in a methane conversion reactor that was operating at $850-950^{\circ} \mathrm{C}$. An oxygen permeation flux of $\approx 10 \mathrm{scc} \cdot \mathrm{cm}^{-2} \cdot \mathrm{min}^{-1}$ was obtained at $900^{\circ} \mathrm{C}$ in a tubular membrane with a wall thickness of 0.75 $\mathrm{mm}$. Using a gas-tight electrochemical cell, we have also measured the steady-state oxygen permeability of flat $\mathrm{Sr}_{2} \mathrm{Fe}_{2} \mathrm{CoO}_{6+\delta}$ membranes as a function of temperature and oxygen partial pressure $\left(\mathrm{pO}_{2}\right)$. Steady-state oxygen permeability increases with increasing temperature and with the difference in $\mathrm{pO}_{2}$ on the two sides of the membrane. At $900^{\circ} \mathrm{C}$, an oxygen permeability of $\approx 2.5 \mathrm{scc} \cdot \mathrm{cm}^{-2} \cdot \mathrm{min}^{-1}$ was obtained in a $2.9-\mathrm{mm}$-thick membrane. This value agrees with that obtained in methane conversion reactor experiments. Current-voltage (I-V) characteristics determined in the gas-tight cell indicate that bulk effect, rather than surface exchange effect, is the main limiting factor for oxygen permeation of $\approx 1$ mm-thick $\mathrm{Sr}_{2} \mathrm{Fe}_{2} \mathrm{CoO}_{6+\delta}$ membranes at elevated temperatures $\left(>650^{\circ} \mathrm{C}\right)$.
\end{abstract}

\section{INTRODUCTION}

In recent years, mixed-conducting oxides, in which both ionic and electronic charge carriers exist, have received increased attention because of their technological importance in high-temperature electrochemical devices and in electrocatalysis [1-6]. For example, they are used as sensors and electrodes in solid-state fuel cells; if their ionic conductivity is high enough, they can be used as dense membranes for gas separation. It is generally accepted that mixed-conducting oxide membranes have great potential to meet the needs of many segments of the oxygen market. The applications envisioned range from small-scale oxygen pumps for medical applications to large-scale usage in combustion processes such as coal liquefaction.

$\mathrm{Sr}-\mathrm{Fe}-\mathrm{Co}-\mathrm{O}$ exhibits not only high combined electronic and oxygen ionic conductivity but also high oxygen permeability $[7,8]$. It is a good candidate material as a dense membrane for separation of high-purity oxygen. In an oxygen separation reactor with membranes of this type, oxygen can be transported from the high- $\mathrm{pO}_{2}$ side to the low- $\mathrm{pO}_{2}$ side under the driving force of the $\mathrm{pO}_{2}$ difference, $\Delta \log \left(\mathrm{pO}_{2}\right)$, without the need for external electrical circuitry. Extruded tubular membranes made of $\mathrm{Sr}$ $\mathrm{Fe}-\mathrm{Co}$ oxide have been tested in a prototype methane conversion reactor that was used for partial oxidation of methane to produce syngas $\left(\mathrm{CO}+\mathrm{H}_{2}\right)$. Methane conversion efficiencies of $>98 \%$ were observed and the reactor tubes have operated for $>1000 \mathrm{~h}[9,10]$. Moreover, the oxygen flux obtained from the separation of air in this type of conversion reactor is considered commercially feasible. The use of this technology can significantly reduce the cost of oxygen separation [11-13].

In this paper, we report the oxygen permeability that was obtained for a $\mathrm{Sr}_{2} \mathrm{Fe}_{2} \mathrm{CoO}_{6+\delta}$ disk ceramic membrane that was measured in a gas-tight electrochemical cell experiment. I-V characteristics of the gas-tight cell were examined to determine the surface effect of the dense $\mathrm{Sr}_{2} \mathrm{Fe}_{2} \mathrm{CoO}_{6+\delta}$ ceramic membrane. Activation energy was derived from temperature-dependent steady-state oxygen permeation data.

\section{EXPERIMENTAL}

$\mathrm{Sr}_{2} \mathrm{Fe}_{2} \mathrm{CoO}_{6+\delta}$ powder was made by mixing and grinding appropriate amounts of $\mathrm{SrCO}_{3}$, $\mathrm{Fe}_{2} \mathrm{O}_{3}$, and $\mathrm{Co}\left(\mathrm{NO}_{3}\right)_{2} \cdot 6 \mathrm{H}_{2} \mathrm{O}$ in isopropanol with zirconia media for $15 \mathrm{~h}$. After drying, the mixture 
was calcined in air at $850^{\circ} \mathrm{C}$ for $16 \mathrm{~h}$, with intermittent grinding. After the final calcination, the powder was ground with an agate mortar and pestle to an average partical size of $\approx 7 \mu \mathrm{m}$. The resultant powder was characterized by $\mathrm{X}$-ray diffraction and scanning electron microscopy to ensure its phase integrity. The powder was pressed with a $120-\mathrm{MPa}$ load into pellets, $21.5 \mathrm{~mm}$ in diameter and $\approx 2-5 \mathrm{~mm}$ thick. The pellets were then sintered at $\approx 1200^{\circ} \mathrm{C}$ in air for $5 \mathrm{~h}$. The sintered pellets were subsequently polished and used for permeation tests.

A schematic diagram of the gas-tight electrochemical cell used in our experiments is shown in Fig. 1. A sintered pellet of $\mathrm{Sr}_{2} \mathrm{Fe}_{2} \mathrm{CoO}_{6+\delta}$ was sealed to a yttria-stabilized zirconia (YSZ) crucible with a Pyrex glass seal. Electrical leads (10-mil Pt wires) are separated from the YSZ crucible and

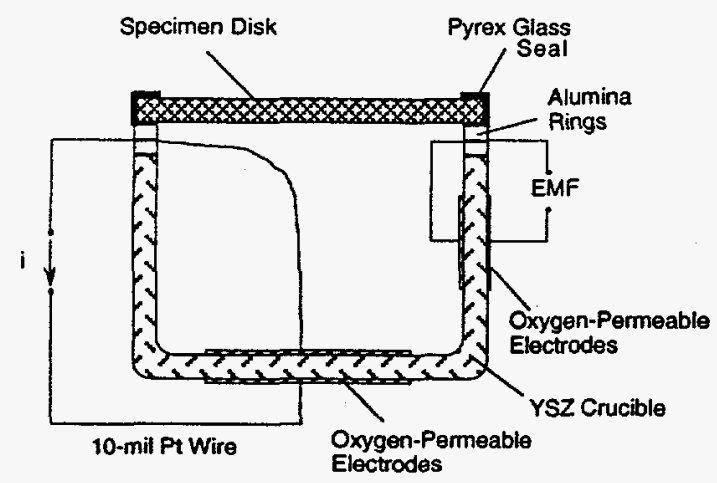

Fig. 1. Schematic drawing of cross-sectional view of gastight electrochemical cell used to measure oxygen permeability.

$\mathrm{Sr}_{2} \mathrm{Fe}_{2} \mathrm{CoO}_{6+\delta}$ disk membrane by two alumina rings. Electrodes were made on the bottom and side of the YSZ crucible. The bottom electrodes were used to pump oxygen from the gas-tight cell, whereas the other electrodes were used to detect the $\mathrm{pO}_{2}$ inside the cell. The $\mathrm{pO}_{2}$ inside the cell can be determined from the electromotive force (EMF) E generated on the side wall of the YSZ crucible by solving,

$$
\mathrm{pO}_{2}^{\mathrm{II}}=\mathrm{pO}_{2}^{\mathrm{I}} \exp \left(\frac{4 \mathrm{FE}}{\mathrm{RT}}\right)
$$

where $\mathrm{pO}_{2}{ }^{\mathrm{II}}$ and $\mathrm{pO}_{2}{ }^{\mathrm{I}}$ are the $\mathrm{pO}_{2}$ values inside and outside the gas-tight cell, respectively. Other variables are as usual, i.e., F, Faraday's constant; R, gas constant; and T, absolute temperature. Reducing oxygen environments were achieved by pumping oxygen out from the gas-tight cell by using the pumping electrodes on the YSZ crucible. Oxygen permeates the $\mathrm{Sr}_{2} \mathrm{Fe}_{2} \mathrm{CoO}_{6+\delta}$ disk membrane because of the $\mathrm{pO}_{2}$ difference on the two sides of the membrane. Under steady-state conditions, the amount of oxygen that enters the cell (by permeating the specimen disk) is equal to that pumped out by the YSZ oxygen pump. Therefore, the flow of oxygen through the specimen can be determined from the current applied to the YSZ oxygen pump. Oxygen permeation flux $\mathrm{jO}_{2}$ (in $\mathrm{mol} \cdot \mathrm{cm}^{-2} \cdot \mathrm{s}^{-1}$ ) is related to the applied current I (in A) by

$$
\mathrm{jO}_{2}=\frac{\mathrm{I}}{4 \mathrm{FS}}
$$

where $S$ is the effective cross-sectional area of the specimen.

\section{RESULTS AND DISCUSSION}

The EMF generated on the sensor electrodes as a function of pumping current at various temperature is plotted in Fig. 2. At a given temperature, the EMF on the sensor electrodes increases with increasing pumping current; EMF increases with decreasing temperature at a given pumping current, and the pumping current increases with increasing temperature to achieve a specific EMF value because the oxygen permeability is higher at a higher temperature.

During our experiment, the gas-tight cell was surrounded with flowing air. The $\mathrm{pO}_{2}$ inside the cell can be determined by solving Eq. 1 . The oxygen permeation flux has been calculated from the steadystate pumping current by solving Eq. 2. To examine

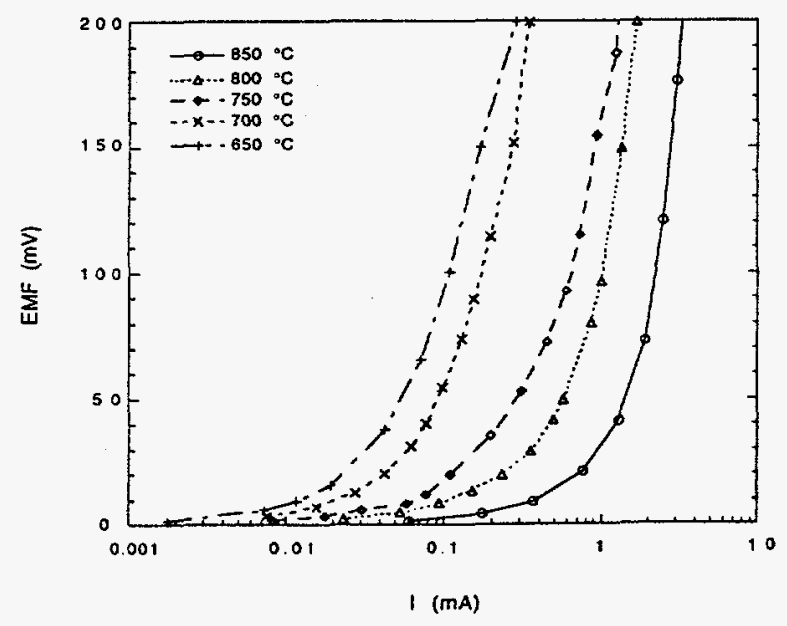

Fig. 2. Electromotive force as a function of pumping current at various temperatures. 
the contributions of bulk and interface effects to the oxygen permeation mechanism of the $\mathrm{Sr}_{2} \mathrm{Fe}_{2} \mathrm{CoO}_{6+\delta}$ sample, we fit the permeation data into the following equation [14]:

$$
\mathrm{jO}_{2}=\alpha\left[\left(\mathrm{pO}_{2}^{\mathrm{I}}\right)^{\mathrm{r}}-\left(\mathrm{pO}_{2}^{\mathrm{Il}}\right)^{\mathrm{r}}\right]
$$

where $r$ is the kinetic order in oxygen of the surface reaction and $\alpha$ is the exchange rate at $\mathrm{pO}_{2}=1 \mathrm{~atm}$. For a permeation process where the surface reaction (exchange) effect is the controlling factor, we would have $r=1 / 2$. The surface exchange constant $\alpha$ (in $\mathrm{cm} \cdot \mathrm{min}^{-1} \cdot \mathrm{atm}^{-1 / 2}$ ) can be determined by a least-square fitting of the experimental data. For the case where the bulk effect is the controlling factor or, in another words, the surface exchange rate is sufficiently large, oxygen permeation flux can be represented as [15]:

$$
\mathrm{j}_{2}=\frac{\beta}{\mathrm{L}}\left[\left(\mathrm{pO}_{2}^{\mathrm{I}}\right)^{1 / 4}-\left(\mathrm{pO}_{2}^{\mathrm{II}}\right)^{1 / 4}\right]
$$

where $\mathrm{L}$ is the thickness of the membrane (in $\mathrm{cm}$ ) and $\beta$ is a bulk diffusion parameter (in $\mathrm{cm}^{2}$. $\mathrm{min}^{-1} \cdot \mathrm{atm}^{-1 / 4}$ ). Figure 3 shows typical oxygen permeation data as a function of the $\mathrm{pO}_{2}$ inside the cell, along with the least square-fittings to Eq. 3 (with $r=0.5$ ) and Eq. 4 (with $r=0.25$ ). The fitting is much better to Eq. 4 than to Eq. 3, indicates that bulk diffusion plays the controlling role in the oxygen permeation process in the $\mathrm{Sr}_{2} \mathrm{Fe}_{2} \mathrm{CoO}_{6+\delta}$ membrane of thickness $\approx 1 \mathrm{~mm}$ at high temperatures $\left(>650^{\circ} \mathrm{C}\right)$.

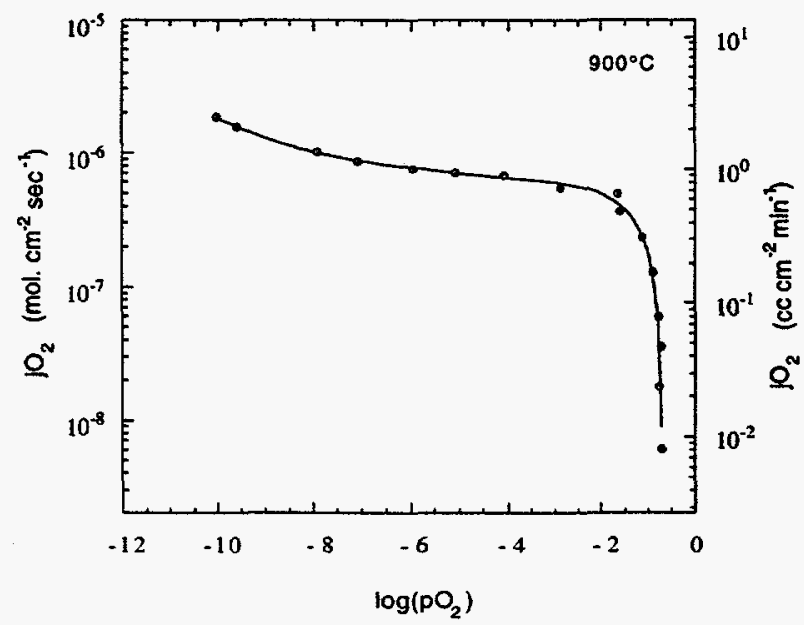

Fig. 4. The $\mathrm{pO}_{2}$ dependence of steady-state oxygen permeation flux for a 2.9 -mm-thick disk membrane.

becomes flatter when $\mathrm{pO}_{2}$ inside the cell is reduced further. Results on oxygen permeability at various $\mathrm{pO}_{2}$ gradients and temperatures show that, as expected, $\mathrm{jO}_{2}$ increases with temperature and $\mathrm{pO}_{2}$ gradients. At $900^{\circ} \mathrm{C}$, oxygen permeability was $\approx 2.5$ $\mathrm{scc} \cdot \mathrm{cm}^{-2} \cdot \mathrm{min}^{-1}$ for a $2.9-\mathrm{mm}$-thick specimen and it increased as membrane thickness decreased.

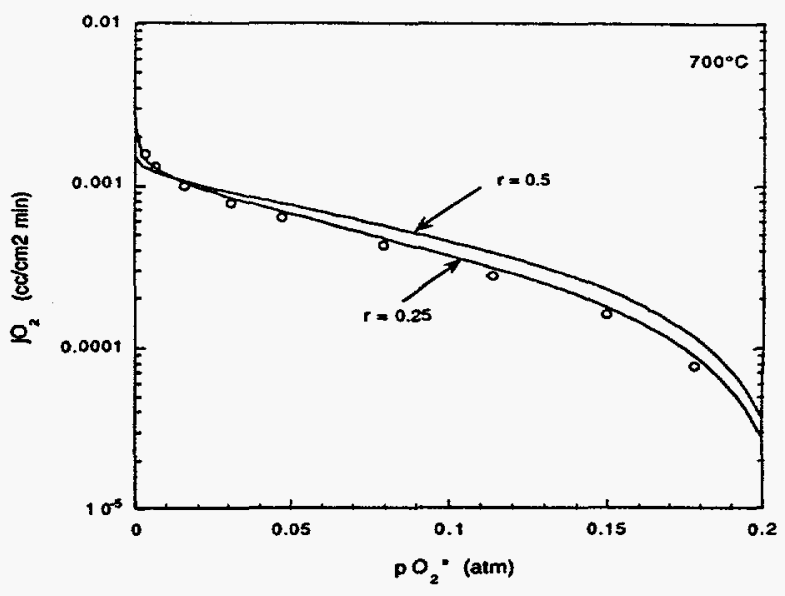

Fig. 3. Steady-state oxygen permeation flux as a function of $\mathrm{pO}_{2}$ inside the gas-tight cell, and its fitting to Eqs. 3 $(r=0.5)$ and $4(r=0.25)$.

In Fig. 4, the steady state oxygen permeation flux of a 2.9 -mm-thick pellet specimen at $900^{\circ} \mathrm{C}$, determined by solving Eq. 2, is plotted as a function of the $\mathrm{pO}_{2}$ inside the gas-tight cell. The figure 4 shows that $\mathrm{jO}_{2}$ increases dramatically in the range between $\mathrm{pO}_{2}=0.21$ and $\approx 10^{-3}$ atm, and its slope

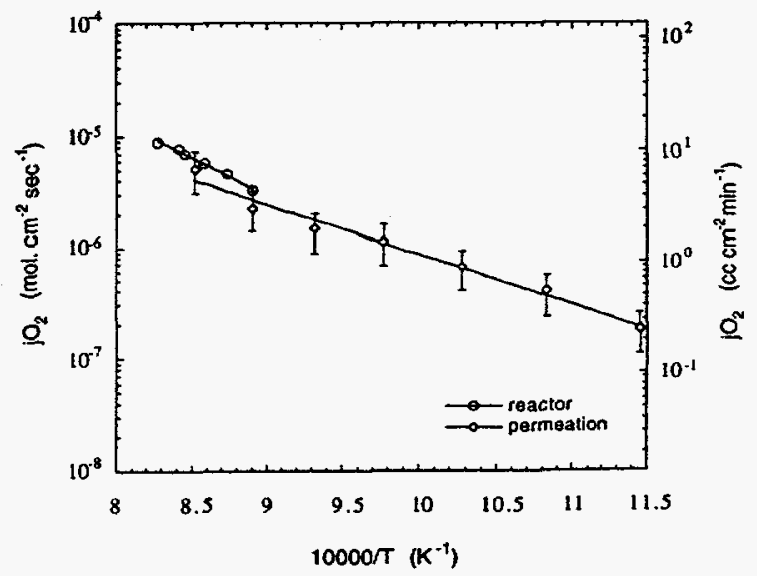

Fig. 5. Temperature dependence of oxygen permeation flux obtained from methane conversion reactor and gas-tight cell. 